University of Nebraska - Lincoln

DigitalCommons@University of Nebraska - Lincoln

U.S. Department of Veterans Affairs Staff

Publications

U.S. Department of Veterans Affairs

2007

\title{
Building a better virus trap
}

Clara Davis Long

Stanford University

Katie Turner-Shelef

Stanford University

David A. Relman

Stanford University School of Medicine, relman@stanford.edu

Follow this and additional works at: https://digitalcommons.unl.edu/veterans

Davis Long, Clara; Turner-Shelef, Katie; and Relman, David A., "Building a better virus trap" (2007). U.S. Department of Veterans Affairs Staff Publications. 23.

https://digitalcommons.unl.edu/veterans/23

This Article is brought to you for free and open access by the U.S. Department of Veterans Affairs at DigitalCommons@University of Nebraska - Lincoln. It has been accepted for inclusion in U.S. Department of Veterans Affairs Staff Publications by an authorized administrator of DigitalCommons@University of Nebraska - Lincoln. 


\title{
Building a better virus trap
}

\section{Clara Davis Long ${ }^{1}$, Katie Turner-Shelef ${ }^{2}$ and David A. Relman ${ }^{1,3,4}$}

\author{
${ }^{1}$ Department of Microbiology and Immunology, Stanford University, 299 Campus Drive, Stanford, CA 94305, USA \\ ${ }^{2}$ Department of Biological Sciences, Stanford University, 299 Campus Drive, Stanford, CA 94305, USA \\ ${ }^{3}$ Department of Medicine, Stanford University, 299 Campus Drive, Stanford, CA 94305, USA \\ ${ }^{4}$ Veterans Affairs, Palo Alto Health Care System, 3801 Miranda Avenue 154T, Palo Alto, CA 94304, USA
}

\begin{abstract}
The concept of ecological 'traps' is based in theory from ecology and conservation biology that has now found application to infectious diseases with a study from Paul Turner's group. This study is important because it offers a mathematical model of ecological traps, applies this model to viruses, and tests the model in a bacteriaphage system. Although there will be technical hurdles to overcome, this concept might lead to benefits for both health and industry.
\end{abstract}

\section{Ecological traps}

An ecological trap is defined as a habitat that is suboptimal for growth or for reproduction of a population, but that is preferred to the optimal habitat by members of the population [1], typically in response to a specific environmental cue [2]. The concept has primarily been a topic of concern in conservation biology, invoked when species of interest choose an anthropogenically altered habitat over a more pristine counterpart, resulting in a negative effect on the population [3]. The concept of the ecological trap derives from source-sink theory. This theory postulates that there are certain habitats for any given species that provide superior conditions for population growth, and which are therefore a source for individuals and genes moving to other habitat-types. The theory further postulates that other habitat-types support low or no reproduction, and are 'sinks' for individuals or genes from the sourcehabitats; these populations are only maintained by continued emigration from the sources. A trap differs from a sink in that a trap habitat is actively preferred over the most suitable habitat, or source. Therefore, individuals are attracted to this unsuitable habitat, and the population might become trapped there, unable to maintain reproduction at a high enough level to sustain the population.

Organisms are thought to follow specific environmental cues that identify high-quality habitats and lead to optimization of organism fitness. Over time, populations presumably evolve to recognize cues from what are, by definition, the most favorable habitats. However, ecological traps occur when sub-optimal habitats present the same cues as the optimal habitat, luring the organism away from the optimal habitat, and resulting in a decline in organism fitness. What was once a specific adaptation for choosing the best habitat therefore becomes maladaptive. One frequently cited example is that of sea turtle

Corresponding author: Relman, D.A. (relman@stanford.edu). hatchlings following artificial lights. Light cues on the horizon signaled the direction of the ocean, until recently when humans introduced artificial lighting from beachfront properties - in the opposite direction of the ocean [4]. Traps such as this are suspected to exist in many contexts in which the environment has changed quickly, and the ability of the organism to discriminate between habitats has not had time to compensate [5].

In contrast to the central goal of conservation biology, which seeks to preserve rare species, ecological traps can be used to manipulate an undesirable species toward extinction. This approach has been investigated in agricultural systems, in which various species of plants can be used to attract insect pests away from commercial crops [6]. The concept of the trap might also be used in medicine, for example to trap agents of disease in, or on, the human body. The trap habitat concept seems particularly appropriate for the fight against viral disease. For instance, a cell might attract and bind viruses by expressing appropriate receptors on its surface, but then fail to support viral replication, and thereby trap virions either inside the cell or on the cell exterior, leading to their clearance from the body.

\section{Experimental creation of traps}

Although they have been discussed for several decades, ecological traps have been difficult to study experimentally, because of the numerous factors required for creation of these traps, and the lack of mechanistic understanding of the way in which traps operate [2]. Microbial systems might provide an optimal system for the study of ecological traps, not only because multiple inputs can be controlled, but also because there are many immediately relevant applications to infectious diseases. Dennehy et al. [7] constructed a mathematical model of virus growth-rate based on the frequency of trap cells in the environment and varying levels of trapping-efficacy, with the goal of calculating the frequency of trap cells necessary to drive a virus population to extinction. This is dependent on trapping efficacy, with a higher frequency required for extinction if efficacy is low. The threshold can decrease or increase if trap-cell efficacy is frequency-dependent, such that the ability to trap depends on the proportion of trap cells in the population. In this model, the lowest level at which the virus population was driven to extinction occurred when the efficacy of the trap cells decreased as their population numbers increased. The model was also expanded so as to include a virus-loss rate, reflecting factors such as predation (immune function) and emigration (wash-out) [7]. 
This mathematical model was tested in a laboratory system using live Pseudomonas phaseolicola bacteria and phage phi6. Phi6 binds to type IV pili of $P$. phaseolicola, and enters the cell as the pili are retracted. Three naturally occurring cell types were used in this experiment: (i) the normal host cell; (ii) a neutral host cell that does not express type IV pili, and (iii) the trap cell, which is a super-producer of type IV pili. Super-producers present many pilus phage-attachment sites, but do not retract these pili, which prevents phage from entering the cell (Figure 1). The neutral non-trap cells were used to determine if effects on the phage population were dependent on the reduction in frequency of host cells, rather than on the action of the traps. Phage attached to trap cells more than three times faster than to wild-type cells. The efficacy of these trap cells was tested in two types of environments: (i) spatially unstructured (incubated while shaken in broth); and (ii) spatially structured (grown on an agar plate). Efficacy of the traps was determined to be frequencyindependent in the well-mixed, unstructured environment, but exhibited negative frequency-dependence in the spatially structured environment, in that trap efficacy decreased with increasing trap frequency (Figure 2). The mathematical model predicted that in such cases of negative frequency-dependence, the threshold of trap cells needed to drive the virus population to extinction would be lower. Serial passage experiments were conducted in the spatially structured environment to verify the concept that trap cells could drive virus populations to extinction. In agreement with the predictions of the model, a bacterial population containing 50\% trap cells was sufficient to drive the viral populations to extinction, whereas the viral population was sustained when the bacterial population contained 50\% neutral non-host cells.

\section{Application of traps to clinical settings}

Previous work has established the possibility of ecological traps as a tool for fighting viral infections. Asher et al. [8] explored the use of erythrocytes as virus-traps, based on the concept that they can be engineered to express viral receptors, but are unable to support viral replication. Using this concept they developed a transgenic mouse expressing Coxsackie adenovirus receptor (CAR) on erythrocytes, and infected the transgenic mice with a murineadapted Coxsackievirus. The mice expressing CAR showed reduced viral replication, reduced viremia, and increased survival compared with control mice. The authors suggested that treatment might involve transfusion of cells, rather than host genetic manipulation. Asher et al. proposed various methods by which erythrocytes might be decorated with viral receptor proteins such as CAR.

Ecological traps as a treatment approach might provide several benefits compared with other methods. First, ecological traps can be designed to be highly specific for particular infectious agents. Unlike a 'scorched earth' method that kills off many species (e.g. widespread pesticide use or

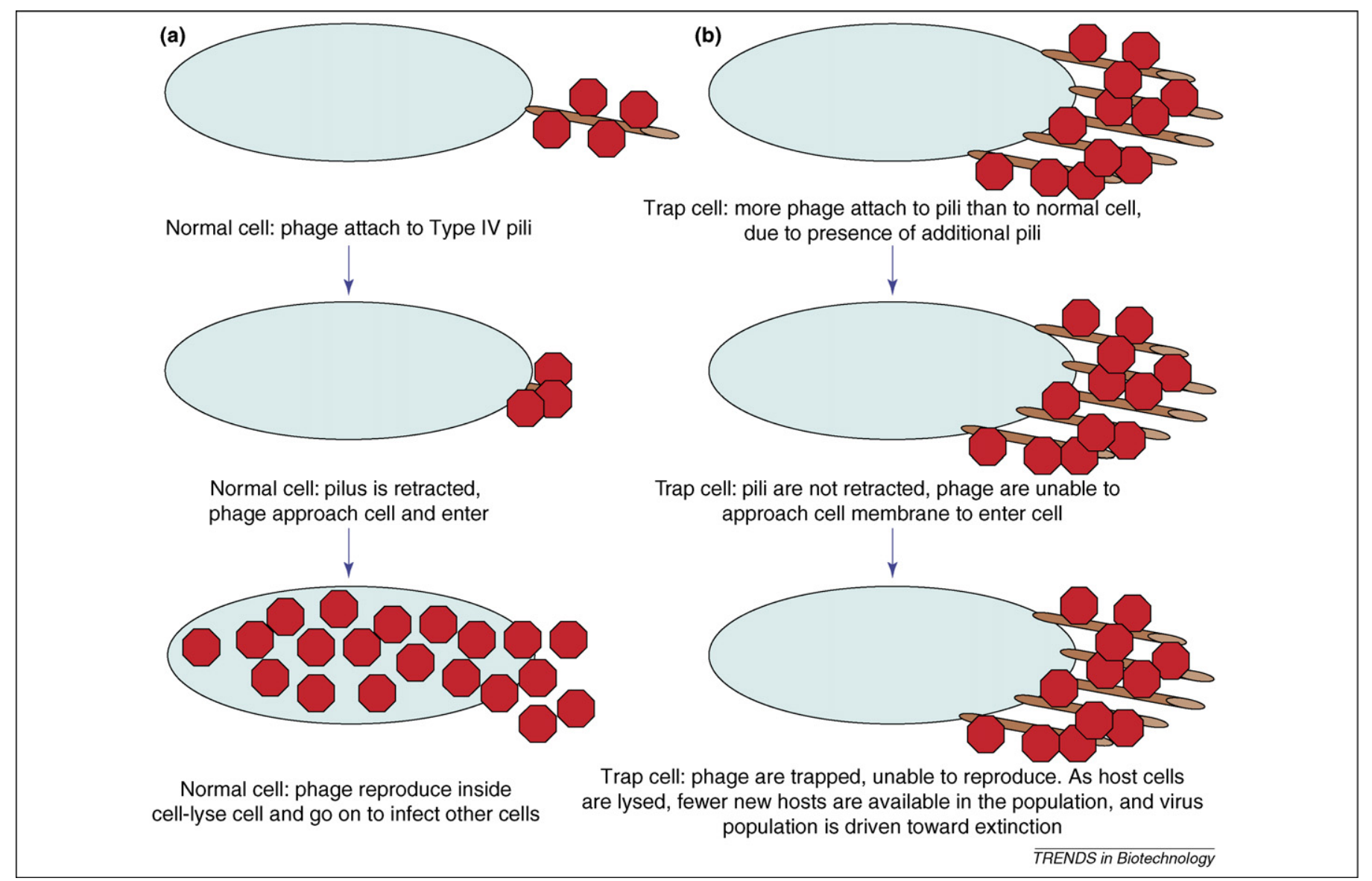

Figure 1. Conceptual illustration of trap cells: phage are trapped by binding to receptors that are unable to mediate viral entry and the phage are therefore unable to reproduce. 


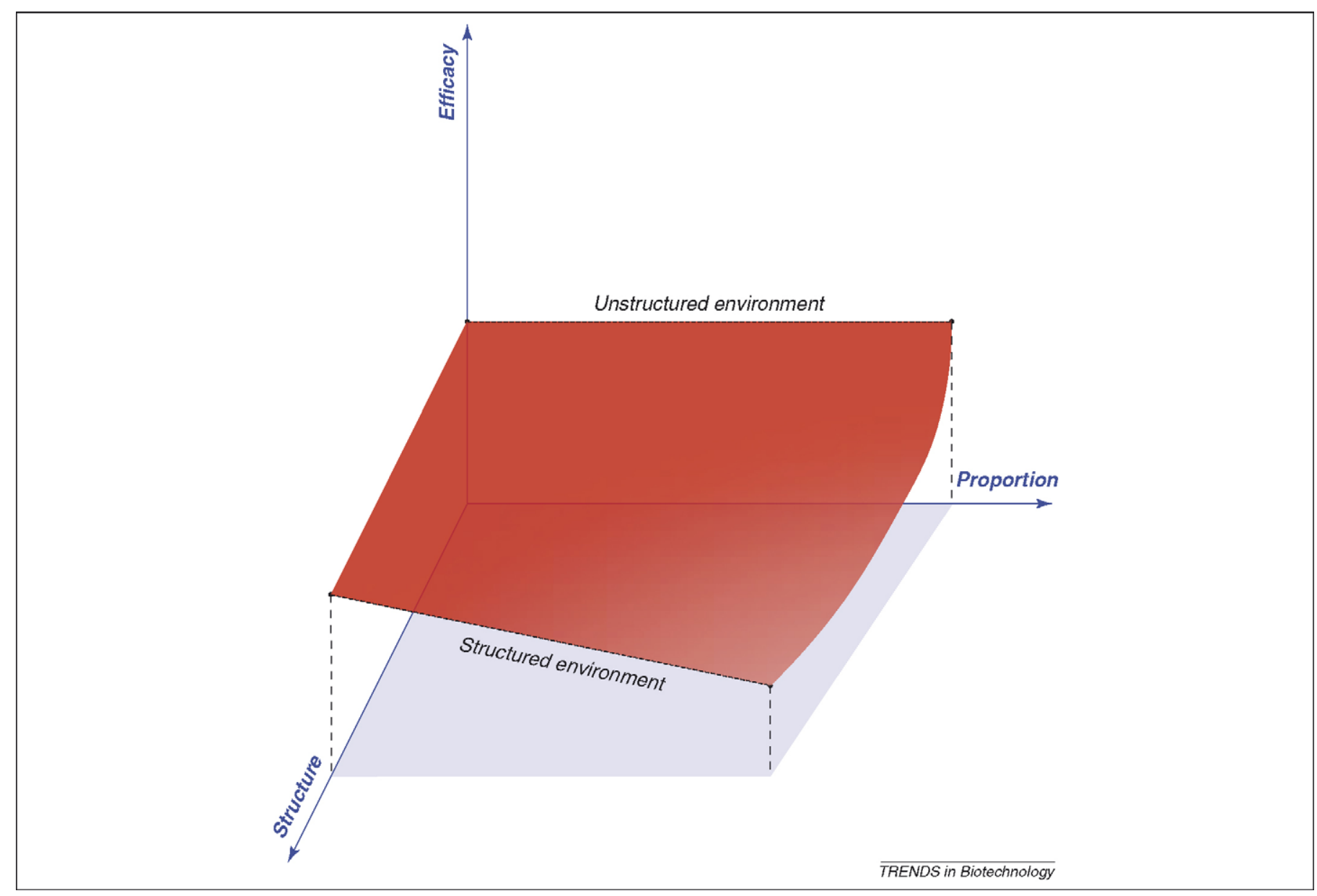

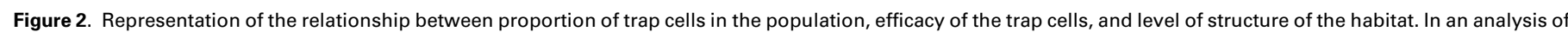

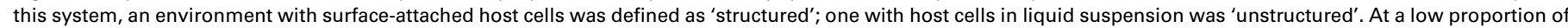

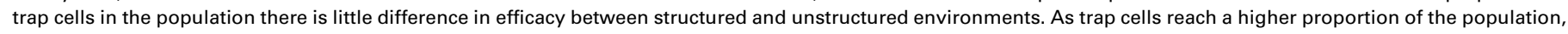
their efficacy decreases in the structured environment, but remains the same in the unstructured environment.

broad-spectrum antibiotics), ecological traps described in the literature are species-specific [2]. Such directed treatment might avoid the risk of altering complex ecosystems, which has been observed in the use of broad-spectrum antibiotics to combat human infectious diseases. The consequences of disrupting complex beneficial indigenous microbial communities can be substantial, as exemplified by the serious problems of Clostridium difficile-associated diarrhea, and the emergence of multi-drug resistant bacterial pathogens. In addition, the principle of ecological traps will be applicable to any category of infectious agents, such as bacterial, viral, and eukaryotic pathogens, which require a host-specific habitat for their replication.

Although trap cells might present an attractive new approach for treating or preventing infectious diseases, substantial hurdles need to be overcome before clinical implementation of this concept. Engineering cells such as erythrocytes to express particular receptors is feasible, but difficulties will arise regarding the required number of cells. In the system of Dennehy et al. at least $50 \%$ of the target-cell population needed to be trap cells to drive phage to extinction. This level of cell replacement or supplementation will be difficult to achieve in the human body. However, in practice the actual level of trap cells needed to eliminate a viral population is reduced by the multiple available mechanisms for elimination, or 'wash-out', of viral particles. The wash-out rate is considered as a single variable in the model, and includes death and migration out of the system. In a human body this wash-out term needs to be expanded to reflect multiple independent variables, and should include not only excretion of virions by the body, but the actions of the immune system and of antivirals, reducing the population size.

Another potential pitfall of applying trap cells could arise if a virus with a high mutation rate evolved to reject the engineered receptor and interacted with an alternate receptor. The selection for this type of mutation would be strong. Any virus mutant that arose could avoid the trap cells and would spread rapidly through a viral population. Trap cells might therefore be best implemented as a complementary strategy to antiviral therapy and vaccination. Trap cells might also provide a new form of prophylaxis because trap cells could be introduced before or soon after exposure. By introducing high levels of trap cells, the size of the viral population could be reduced early in the infection cycle and therefore prevent the occurrence of symptoms and signs of disease. Engineered cells with a short lifespan would provide an ideal means of such short-term prophylaxis.

Virus traps might have further applications in industrial settings For instance, phages that prey on lactic acid bacteria are a major problem in the dairy industry. The 
development of particular strains of bacteria as phagetraps could prevent economic losses owing to phage in these systems, as long as these strains did not adversely affect the fermentation process. Because of their economic importance, the biology of lactic acid bacteria and their phages has been studied extensively, making this an area in which trap-cell approaches might be implemented in the near future. The selective nature of trap cells makes their application in dairy production particularly promising because some phage are suspected to be beneficial to the production process; trap cells could be employed to bind or attract in a specific manner phage detrimental to dairy production, while allowing the proliferation of phage meant to control potential pathogens [9].

\section{Conclusion}

The work of Dennehy et al. [7] has major implications for the development of a model that could be used to describe the behavior of trap cells and viruses. Quantification of trap behavior and performance will be important for the translation of this concept into practice. A basic model of trap cell and virus behavior can then be expanded to include additional factors, such as elements of the immune system, and can be parameterized for specific human infections. Adding these factors to the model will be an important step forward for the development of therapies, and should be pursued particularly for human viruses. However, a defined model of trap function such as this will also be adaptable to the needs of agriculture or industry, making this work more widely applicable.

\section{References}

1 Dwernychuck, L.W. and Boag, D.A. (1972) Ducks nesting in association with gulls-an ecological trap? Can. J. Zool. 50, 559-563

2 Robertson, B.A. and Hutto, R.L. (2006) A framework for understanding ecological traps and an evaluation of existing evidence. Ecology 87, 1075-1085

3 Battin, J. (2004) When good animals love bad habitats: ecological traps and the conservation of animal populations. Conserv. Biol. 18, 1482 1491

4 Witherington, B.E. (1997) The problem of photopollution for sea turtles and other nocturnal animals. In Behavioral Approaches to Conservation in the Wild (Clemmons, J.R. and Bucholz, R., eds), pp. 303-328, Cambridge University Press

5 Schlaepfer, M.A. et al. (2002) Ecological and evolutionary traps. Trends Ecol. Evol. 17, 474-480

6 Shelton, A.M. and Badenes-Perez, F.R. (2006) Concepts and applications of trap cropping in pest management. Annu. Rev. Entomol. 51, 285-308

7 Dennehy, J.J. et al. (2007) Virus population extinction via ecological traps. Ecol. Lett. 10, 230-240

8 Asher, D.R. et al. (2005) The erythrocyte viral trap: transgenic expression of viral receptor on erythrocytes attenuates coxsackievirus B infection. Proc. Natl. Acad. Sci. U. S. A. 102, 12897-12902

9 McGrath, S. et al. (2007) Bacteriophages in dairy products: Pros and cons. Biotechnol J 2, 450-455

\section{Elsevier.com - linking scientists to new research and thinking}

Designed for scientists' information needs, Elsevier.com is powered by the latest technology with customer-focused navigation and an intuitive architecture for an improved user experience and greater productivity.

The easy-to-use navigational tools and structure connect scientists with vital information - all from one entry point. Users can perform rapid and precise searches with our advanced search functionality, using the FAST technology of Scirus.com, the free science search engine. Users can define their searches by any number of criteria to pinpoint information and resources. Search by a specific author or editor, book publication date, subject area - life sciences, health sciences, physical sciences and social sciences - or by product type. Elsevier's portfolio includes more than 1800 Elsevier journals, 2200 new books every year and a range of innovative electronic products. In addition, tailored content for authors, editors and librarians provides timely news and updates on new products and services.

Elsevier is proud to be a partner with the scientific and medical community. Find out more about

our mission and values at Elsevier.com. Discover how we support the scientific, technical and medical communities worldwide through partnerships with libraries and other publishers, and grant awards from The Elsevier Foundation.

As a world-leading publisher of scientific, technical and health information, Elsevier is dedicated to linking researchers and professionals to the best thinking in their fields. We offer the widest and deepest coverage in a range of media types to enhance cross-pollination of information, breakthroughs in research and discovery, and the sharing and preservation of knowledge.

Elsevier. Building insights. Breaking boundaries. www.elsevier.com 